\title{
The position, dimensions and morphological variations of mental foramen in mandibles
}

\author{
LBL Prabodha ${ }^{1}$, BG Nanayakkara ${ }^{2}$ \\ ${ }^{1}$ Lecturer in Anatomy, ${ }^{2}$ Senior Lecturer in Anatomy, Faculty of Medicine, University of Ruhuna, \\ Galle
}

\begin{abstract}
Introduction: Mental foramen (MF) is a small foramen situated in antero lateral aspect of the body of the mandible. It transmits mental nerve, artery and vein. Studying the position and its morphological variations of MF helps to localise the mental nerve which is a branch of the inferior alveolar nerve. It will help to prevent complications during invasive procedures at the mental region. The most common position of the MF is in-line with the longitudinal axis of the $2^{\text {nd }}$ pre-molar tooth followed by a location between the $1^{\text {st }}$ and the second pre-molar tooth. It is usually single and oval in shape.
\end{abstract}

Materials and methods: This study was carried out in the Department of Anatomy Faculty of Medicine, University of Ruhuna. 24 hemimandibles were examined and out of which there were 15 Male and 09 Female subjects. The age ranged from 47 years to 103 years. Measurements were obtained by using a vernior caliper. Distance from (a) Symphysis menti, (b) Inferior border of the mandible, (c) Posterior border of the ramus and (d) Superior border of the body of the mandible to the MF and the diameters of the MF were taken in to the nearest $1 / 10$ of the millimeter.

Results and discussion: Mean age was 74.73 years in males and 75.43 years in females. Out of 24 hemi-mandibles 22 (91.67\%) posses single MF and Two (8.33\%) had accessory MF's. The accessory MF's were smaller in size (mean diameter $1.70 \mathrm{~mm}$ ) than the regular MF (Mean diameter $2.11 \mathrm{~mm}$ in round shape and mean long diameter was $2.97 \mathrm{~mm}$ in oval shape MF) and were oval in shape. The mean distance from symphysis menti, posterior border of the ramus, and inferior border of the body of the mandible were $26.52 \mathrm{~mm}, 65.38 \mathrm{~mm}, 12.25 \mathrm{~mm}$ respectively.

Conclusion: There was no significant difference in the shape, position and age related variation of the MF with similar studies, but a significant difference can be seen in the size of the MF in Sri Lankan mandibles. 


\section{Introduction}

Mental foramen (MF) is a small foramen situated in antero lateral aspect of the body of the mandible. It transmits mental nerve, artery and vein [1]. Mental nerve is a branch of the inferior alveolar nerve which supplies sensation to the lower lip and the labial mucosa [2]. The most useful injection for anesthetising the mandibular teeth is the inferior alveolar nerve block. It is necessary to administer a nerve block in the lower jaw because of the thickness of the dense mandibular cortical bone which prevents adequate diffusion of the solution [2]. To anesthetise the anterior teeth, including the premolars and canines, it is possible to avoid giving inferior alveolar block, by injecting anesthetic solution adjacent to the mental foramen [2]. Although this is termed mental injection or mental nerve block, the aim of the injection is to affect the inferior alveolar and incisive nerves in that region [2]. Studying the position and its morphological variations of MF is very important because it will be helpful to localize the important maxillofacial neurovascular bundle passing through the MF.

The most common position of the MF is in-line with the longitudinal axis of the $2^{\text {nd }}$ pre-molar tooth followed by a location between the $1^{\text {st }}$ and second pre-molar tooth [3]. In a study of mandibles of Asian Indians, MF lies inferior to the $2^{\text {nd }}$ premolar tooth in $75 \%$ of 138 mandibles and in between $1^{\text {st }}$ and $2^{\text {nd }}$ pre-molar tooth [4] in $25 \%$ of 138 mandibles. $6.62 \%$ of 138 mandibles posses accessory MF of Asian Indian mandibles [4]. In the study of 525 dry mandibles, MF was single in $94 \%$ of 525 mandible and posses accessory foramina in $5.33 \%$ of cases [5].

Shape of the MF was round in $34.48 \%$ of 525 mandibles with an average diameter of $1.68 \mathrm{~mm}$ and oval in shape of $65.52 \%$ of cases with an average long diameter of $2.37 \mathrm{~mm}$ [3]. In 32 mandibles of adult black Zimbabweans, the shape of the MF was round in $43.8 \%$ of mandibles [2]. In the study of sixty-nine adult Thai mandibles, the mean distance from the MF to the Symphysis Menti, lower border of the mandible and posterior border of the mandibular ramus was $28.83 \mathrm{~mm}$, $68.85 \mathrm{~mm}$ and $14.88 \mathrm{~mm}$ respectively [6]. Three accessory MFs were found in three Japanese cadavers and their diameters were $0.74 \mathrm{~mm}$,
$0.80 \mathrm{~mm}$ and $0.89 \mathrm{~mm}$ and were relatively smaller than normal MF [7]. Distances between MF and accessory MF were $0.67 \mathrm{~mm}, 2.1 \mathrm{~mm}$ and $5.74 \mathrm{~mm}$ [7].

In children before tooth eruption, MF is closer to the superior margin of the body of the mandible and during the eruption period, MF descends to halfway between the superior and inferior margins of the body of the mandible, and in adults with the teeth preserved, the MF is closer to the inferior border of the body of the mandible [5]. With loss of teeth and the alveolar bone resorption the MF moves upwards closer to the superior border of the mandible and in extreme cases of resorption the MF and the adjacent part of the mandibular canal are open at the superior margin of the body of the mandible [5].

\section{Materials and methods}

This study was carried out in the Department of Anatomy, Faculty of Medicine, University of Ruhuna, Galle, Sri Lanka. 24 hemi-mandibles were examined and out of which there were 15 male and 09 female subjects. The age ranged from 47 years to 103 years. Measurements were obtained using a vernior caliper. Distance from (a) symphysis menti, (b) inferior border of the mandible, (c) posterior border of the ramus and (d) superior border of the body of the mandible to the MF and the diameters of the MF were taken in to the nearest $1 / 10$ of the millimeter. Shape, size, and position of the MF were assessed.

\section{Results and discussion}

Mean age was 74.73 years in males and 75.43 years in females ranging from 47 years to 103 years. Out of 24 hemi-mandibles 22 (91.67\%) posses single MF and two (8.33\%) out of 24 had accessory MF. Shape of the MF was oval in 16 out of 24 hemi-mandibles (66.67\%) and round in shape in 8 out of 24 hemi-mandibles (33.33\%). Shapes of the accessory MF's were oval.

In the present study, shape of the MF was oval in most of the cases. It was $66.67 \%$ and there was no significant difference with the results found in literature. In this study there were two mandibles (8.33\%) with accessory MF, one had accessory 
MF 4.6 mm posterior to the regular MF. But the other one, the accessory MF was located $2.9 \mathrm{~mm}$ inferior to the regular MF and it was an unusual position of an accessory MF. The accessory MF's were smaller in size (mean diameter $1.70 \mathrm{~mm}$ ) than the regular MF (mean diameter $2.11 \mathrm{~mm}$ in round shape and mean long diameter was 2.97 $\mathrm{mm}$ in oval shape) and the shapes were oval. The mean distance to the MF from a) symphysis menti (b) inferior border of the body of the mandible (c) posterior border of the ramus of the mandible were $26.52 \mathrm{~mm}, 12.25 \mathrm{~mm}, 65.38 \mathrm{~mm}$ respectively.

\section{Comparison of the study results with the other studies}

Table 1 - Shape of the MF

\begin{tabular}{|l|l|l|l|}
\hline Shape & $\begin{array}{c}\text { Mbajiorgu } \\
\text { et } \text { al }^{(2)}\end{array}$ & $\begin{array}{c}\text { Gershenson } \\
\text { et } a l^{(4)}\end{array}$ & $\begin{array}{l}\text { Study } \\
\text { results }\end{array}$ \\
\hline Oval & $56.3 \%$ & $65.52 \%$ & $66.67 \%$ \\
Round & $43.8 \%$ & $34.48 \%$ & $33.33 \%$ \\
\hline
\end{tabular}

There was no significant variation of the shape of the MF.

Table 2 - Size of the MF

\begin{tabular}{|l|l|l|}
\hline $\begin{array}{l}\text { Size } \\
\text { (mean diameter) }\end{array}$ & $\begin{array}{r}\text { Gershenson } \\
\text { et }^{\left(\boldsymbol{I}^{(4)}\right.}\end{array}$ & Study results \\
\hline $\begin{array}{l}\text { In oval shape } \\
\text { In round shape }\end{array}$ & $\begin{array}{l}2.37 \mathrm{~mm} \\
1.68 \mathrm{~mm}\end{array}$ & $2.97 \mathrm{~mm}$ \\
$2.11 \mathrm{~mm}$ \\
\hline
\end{tabular}

There was a significant variation in the diameter of the MF.

In an adult with the advancement of the age MF was moved towards the superior border of the body of the mandible. This is mainly because of the loss of teeth and alveolar bone resorption. There is a significant variation of the position of the MF with age. This is also compatible with Gerhensons et al study [5].

Table 3 - Position of the MF.

\begin{tabular}{|l|l|l|}
\hline Mean distance from & Apinhasmit et al [6] & Study results \\
\hline Symphysis pubis & $28.83 \mathrm{~mm}$ & $26.52 \mathrm{~mm}$ \\
Posterior border of the ramus of the mandible & $68.85 \mathrm{~mm}$ & $65.38 \mathrm{~mm}$ \\
Inferior border of the body of the mandible & $14.88 \mathrm{~mm}$ & $12.25 \mathrm{~mm}$ \\
\hline
\end{tabular}

\section{Accessory MF}

Accessory MF is an additional MF which is situated near by the regular MF and usually placed posterior to the MF [7]. In this study one accessory MF which was oval in shape, $1.9 \mathrm{~mm}$ in long diameter, was located $4.6 \mathrm{~mm}$ posterior to the regular MF, is more compatible with Toh $\mathrm{H}$ et al study [7]. However the other accessory MF of the mandible of 68 year old female, which was $1.5 \mathrm{~mm}$ diameter and located $2.9 \mathrm{~mm}$ inferior to the normal MF. This position is not a common position. With the result of this study there was no significant difference of the shape and the position of the MF but there was a significant variation in the size of the MF.

\section{References}

1. Igbigbi PS, Lebona S. The position and dimensions of the mental foramen in adult Malawain mandibles. West African Journal of Medicine 2005; 24: 184-9.

2. Rowe AHR. In: Clinical Dentistry. Blackwell Scientific Publications 1986; 3: 372-83.
3. Mbajiorgu EF, Mawera G, Asala SA, Zivanovic S. Position of the mental foramen in adult black Zimbabwean mandibles: a clinical anatomical study. Central African Journal of Medicine 1998; 44: 24-30.

4. Shankland WE. $2^{\text {nd }}$ The position of the mental foramen in Asian Indians: Journal of Oral Implantology 1994; 20: $118-23$.

5. Gershenson A, Nathan H, Luchansky E. Mental foramen and mental nerve: changes with age. Acta Anatomica 1986; 126: 21-8.

6. Ari I, Kafa IM, Basar Z, Kurt MA. The localization and anthropometry of mental foramen on late Byzantine mandibles: Collateral Anthropology 2005; 29: 233-6.

7. Toh H, Kodama J, Yanagisako M, Ohmori T. Anatomical study of the accessory mental foramen and the distribution of its nerve: Okajimas Folia Anatomy Japan 1992; 69(2-3): 85-8.

8. Apinhasmit W, Methathrathip D, Chompoopong S, Sangvichien S. Mental foramen in Thais: an anatomical variation related to gender and side: Surgical Radiological Anatomy 2006 Apr: (Epub ahead of print). 